\title{
DIENS EN DIENSBAARHEID TOT OPBOU VAN DIE KERK
}

\author{
A C BARNARD
}

\begin{abstract}
Service and Servitude in View of the Edification of the Church

The most important change Christ brings about is that people who, in the past, desired to be served, are now willing to serve. The believer is a person who serves and the church is a service community. The service is comprehensive: we serve God, we serve our fellow believers, we serve in the church, we serve in the world, we serve people when they are in need, wherever they are, and we serve God in our services of worship. Through our serving the church is built up, it grows in depth and width. The foundation and legitimation of all service is the grace of God and the crucifixion and resurrection of Christ. He is the content of all service and at the same time the ultimate example thereof. Every believer as a servant of Christ, is called to service and receives a calling and a task. Conversion and service cannot be separated. Our faith must be "lived" in service. The church should create the space for the service and use the believers, not only as assistants, but as co-workers. To believe means to know what service is and then to serve within the context of that knowledge.
\end{abstract}

Teenoor die klagte wat dikwels gehoor word:

Die lidmate - stel nie belang nie

- is onbetrokke

- werk nie mee in en aan die kerk nie

Word die feit gestel:

Die meeste lidmate wil omvattend dien en wil tot die beskikking van die Here staan, en word hiermee opgeroep om die Here inderdaad te dien en ook in sy kerk te dien.

Teenoor die beskuldiging:

Die kerk verloor al meer sy krag

Dit het ongeloofwaardig geword

Dit raak al meer irrelevant

moet met krag gesê word dat die Here self sy kerk bewaar; dat Hý sy kerk bou en dat $\mathrm{Hy}$ in hierdie werk mense, gelowiges, gebruik. Dit beteken tegelyk 'n appèl op elke gelowige om op te staan en te bely:

Ek staan by die Here en by sy kerk

Ek wil in sy diens gebruik word om te help met die opbou van sy kerk.

Van die drie sleutelbegrippe in die tema, naamlik: dien, bou en kerk, word die klem hier gelê op: 
- die diens en diensbaarheid, op die dienende gemeenskap

- die diens geskied egter met 'n duidelike doel, naamlik die bou of opbou van die kerk, plaaslik en veel wyer

- die kerk is die leef- en werkruimte waar die diens geskied

- die kerk is egter ook die mobilisasiebasis van waaruit die diens in die wêreld geskied.

\section{DIENS, DIENSBAARHEID EN DIENSLEWERING}

\subsection{Die groot omkering in ons denke}

Ons almal wil graag groot en belangrik wees. Ons wil graag erken en gedien word. Jesus keer hierdie hele denkpatroon en ook lewenspatroon om. Dit geld Homself, maar ook vir sy kerk en vir elke dissipel. In sy kerk gaan dit nie meer om gedien en bedien te word nie, maar om te dien. Ons word nie allerlei ereplekke in sy kerk beloof nie, maar opgeroep om te dien, om diensbaar te wees en oral diens te lewer.

Om te dien kom nie uit ons natuurlike hart voort nie. Inteendeel, ons hou nie daarvan nie, ons vermy dit so ver as moontlik, ons haat dit dikwels. Juis hierdie dien word dié uitstaande kenmerk van die kerk van Christus en van sy dissipels. Diens bring dus die groot omkering in ons hele denke en lewe te weeg.

\subsection{Die kerk 'n diensgemeenskap}

Die kerk van Jesus Christus is mense wat Hom leer ken het, wat deur Hom verander is en nou in navolging van Hom 'n gemeenskap geword het wat bereid is om omvattend te dien. Die diepe geheim van die kerk is dat mense wat in hulle sonde dood was, deur Christus uit die wêreld en uit die sonde en onder die mag van die bose uitgehaal is, bevry is, hulle verander en vernuwe het en aan Hom verbind het. Hierdeur word $\mathrm{Hy}$ hulle Here en Hoof en geld sy wil, sy plan en sy gesindheid vir hulle. Deur die geloof in Christus word ons kinders van God en staan ons in die allernouste verhouding tot Hom as Vader.

Die binding aan Christus deur die geloof en die groot verandering deur Hom sodat ons nou kan en wil dien, bring ook ' $n$ radikale verandering te weeg tussen die gelowiges onderling. Hulle ontdek mekaar as broers en susters. Deur die binding aan Christus word hulle ook aan mekaar verbind. So word die kerk die groot gesin van God, die familia Dei. Die wonderlike is dat die groot beginsel wat Christus self voorgeleef het en gestel het vir sy dissipels, ook ewe sterk geld vir die verhouding 
tussen die gelowiges onderling: die diens, diensbaarheid en dienslewering.

\subsection{Diens in en aan die kerk}

Wie glo, is ' $n$ dienaar van God in Christus. Hy is in diens gestel omdat hy Christus as sy Here en Hoof erken het. Hy word gestel in die beginsel van diens. Sy lewe en gedrag word van nou af bepaal deur hierdie diens en diensbeginsel.

Die diens geskied aan die kerk, aan die onderskeie gelowiges, ten behoewe van die werksaamhede wat Christus aan sy kerk toevertrou het. Die kerk is egter ook die leef-en werkruimte waar die diens geskied. Elkeen weet hy/sy is geroep om hier te leef en te werk. Hy moet sy gawes, tyd en kragte wy sodat hierdie kerk beter kan funksioneer, kan leef en getuig, en wat meer is, sodat die kerk self 'n diensgemeenskap kan word.

\subsection{Die diens in die wêreld}

Die kerk leef en werk in die wêreld. Hiér dien hulle hul Here; hiér dien hulle mekaar en saam met mekaar. Elke gelowige staan in diens van Christus en van sy kerk ook in die wêreld. Die gemeente as geheel leef en werk in die wêreld sodat Christus deur sy kerk na die wêreld en sy mense in hulle nood kan kom.

Omdat die kerk wel in die wêreld is, maar nie van die wêreld nie, straal dit ' $n$ lig en boodskap in die wêreld uit. Nooit mag die kerk net met homself besig wees nie. Hier in die wêreld is Christus besig om sy koninkryk te bou. Die bouwerk in die koninkryk geskied ook deur die diens van elkeen in die kerk en in die wêreld.

\subsection{Omvattende diens}

Die diens waarom dit in die kerk gaan en wat lei tot die opbou van die kerk, raak nie slegs enkele aspekte nie, maar is omvattend:

- Die erkenning, navolging, gesprek, die aanbidding, lof en prys - wat op God gerig word. Dit is diens aan God en dien van Hom.

- Die dien van God in die wêreld, wat Hom nie erken en gehoorsaam nie. Hier word só geleef, gespreek, gehandel en gewerk dat dit duidelik word wie God is, watter veranderinge Hý aan 'n mens kan en wil doen.

- Die dien van God in en aan sy gemeente, aan die medegelowiges. Hier 
gaan dit om die goeie sorg vir die gemeente, die arbeid sodat die gemeente goed kan funksioneer.

- Die dien van God saam met die gemeente in die erediens. Hier tree die dien van God in die privaat uit in die openbaar en hier word my dions aan God verenig met die diens van die hele gemeente.

- Die diens aan mense in nood binne die gemeente, maar ook oral in die wêreld. Waar daar ook al nood mag wees, waar mense hulp nodig het, daar word ons diens verlang.

- Die diens op al hierdie verskillende terreine hang ten nouste saam met mekaar en vorm ' $n$ eenheid. Ons kan nie die een doen sonder om by die ander uit te kom nie. Dit is die één diens van elke gelowige en van die kerk.

\subsection{Materiële, sosiale en geestelike diens}

Die diens waartoe ons geroep word is ook nog in ' $\mathrm{n}$ ander sin omvattend, want dit sluit die volgende in:

- Die diens op die terrein van die materiële, die ondersteuning, die hulpverlening, die bystand van mekaar.

- Die diens op die terrein van die sosiale, die verhoudings, die saamlewe en saamwerk van mense, die aangewesenheid op mekaar, die konflikte.

- Die diens op die wye terrein van die geestelike, die godsdienstige, die verhouding tot God en tot die medemens; sake soos vergifnis, versoening, bemoediging, versterking, teregwysing, geestelike bystand, geloofshulp as lewenshulp.

Ook hierdie aspekte van die diens vorm 'n allernouste eenheid.

\subsection{Die nuwe gesindheid}

Die omkering van die denke en lewe om nie meer gedien te word nie, maar om te dien, geskied vanuit 'n nuwe gesindheid. Ons staan nou nie meer afwysend teenoor die saak van diens nie, maar ons wil dit graag doen. Ons verkry 'n gesindheid om te wil dien. Daar kom ' $n$ diensbereidheid, ' $n$ dienswilligheid en ' $n$ diensbaarheid. Geensins kom dit by ons op dat ons van ons aansprake prysgee nie, want daar het ' $n$ nuwe gesindheid gekom.

\section{DIE GROND VIR, DIE MOONTLIKHEID VAN EN DIE EIS TOT DIENS}

Waar word daar aan die kerk en aan die gelowiges die eis tot diens ge- 
stel? Wat is die grond daarvan, die basis waarop dit gebou word? Wat is die motivering of eis tot die diens? Hier sal blyk dat diens nie maar ' $n$ bysaak, ' $n$ vrywillige ekstra is, iets wat maar net so goed nagelaat kan word nie. Nee, dit hoort tot die wese van die kerk. Daarsonder kan die kerk nie waarlik kerk wees nie en is sy boodskap kragteloos.

\subsection{God se barmhartigheid}

Aan die grond van alle diens, die basis daarvan, is altyd die wonderlike boodskap dat die grote en heilige God swak en sondige mense barmhartig is. Hy het dit op baie maniere deur sy Woord bekend laat maak. Hy het dit ook op baie maniere deur die dade van barmhartigheid aan mense bekend laat word. Steeds gaan dit by diens om die "groot dinge/dade wat God gedoen het" (Hand 2:11), om die groot woorde wat Hy gespreek het. In hierdie woorde van God teenoor ons en sy dade wat dit bevestig, gaan dit om sy goedgesindheid teenoor ons, om sy liefde en genade, om sy heil, om sy groot herstel van al die gebroke verhoudings waarin ons staan.

\subsection{Die versoening deur Jesus Christus}

God se barmhartigheid teenoor ons word onweerlegbaar duidelik en kragtig in die koms, die lewe en werk van Jesus Christus, en dan veral in sy dood aan die kruis in ons plek, en sy opstanding waardeur ons saam met Hom uit die sonde en dood lewendig word. In die offer van Christus, die diens by uitnemendheid tot ons heil, lê die diepste grond of basis van al ons diens. In die diens van en aan en deur die kerk, asook van elke gelowige, verneem ons die weerklank van die diens van Christus aan die kruis.

Die grond en moontlikheid en eis tot diens moet altyd weer gesoek word in Christus en in sy volbragte offer. HR Weber het gesê: "Die hele lewe van die gemeente, die lidmate en die ampsdraers, hulle eredienste en hulle gestuur wees in die wêreld, moet steeds gesien word in die lig van hierdie offerdiens."

\subsection{Die saak en boodskap van Jesus Christus}

Die diens, ook dié in en aan die kerk, het tot inhoud die saak van Jesus, die aanbreek van die koninkryk van God onder ons en die oproep om daarop te reageer deur bekering en geloof in Christus. Jesus het die heil en verlossing kom bewerk en hierdie goeie boodskap, hierdie goeie nuus, is die begronding van al ons diens. 


\subsection{Christene wat die kleed van Christus dra}

Christene is mense wat deur Christus geroep, verander en vernuwe is sodat hulle nou as kinders van God Hom as Here en Verlosser volg. Hulle dra die kleed, die amp van Christus. Sy Persoon en werk is die samevatting van die drie groot ampte in die Ou Testament: dié van profeet, priester en koning. Hy vervul hierdie ampte, gee daaraan hulle ware sin en betekenis, en in Hom word al drie ampte een.

Die gelowiges ontvang van Hom hierdie ampte en dra dit in hulle lewe. Elke gelowige is ook:

- profeet, wat spreek wat hy van God hoor

- priester, wat dien uit liefde en namens God, en

- koning, wat in die Naam en krag van Christus heers oor die sonde en die mag van die bose.

In hierdie drievoudige amp is elke gelowige veral betrokke by die omvattende diens.

\subsection{Diens na die voorbeeld van Jesus}

Jesus is nie slegs die grond vir die diens nie en gee nie alleen die opdrag tot diens nie, maar is tegelyk die voorbeeld vir alle diens. Van sy eie Persoon en werk sê Hy: "So is dit ook met die Seun van die mens: Hy het nie gekom om gedien te word nie maar om te dien en sy lewe te gee as losprys vir baie mense" (Matt 20:28). Oor sy werk skryf Paulus: "wat Homself as 'n losprys vir almal gegee het" (1 Tim 2:6). Jesus wat wel die Here en die Seun van God is, het gekom om te dien en dít tot aan die uiterste van die dood aan die kruis. Ons moet Christus se voorbeeld navolg, en dan in dubbele sin, naamlik sy liefde (Luk 6:40) en in sy lyding (Luk 22:27). Die dissipels van Jesus mag daarom nie so begaan wees oor die ereposisies in die koninkryk van God nie (Mark 10:37), hulle moet nie soek daarna om hoër as hulle Meester te wees nie (Matt 10:24,25; $20: 26,27)$, maar moet bereid wees om in navolging van Hom en die voorbeeld wat $\mathrm{Hy}$ gestel het, te dien al kos dit wat. As $\mathrm{Hy}$ as die Here en Meester bereid was om nederige slawewerk te doen deur sy dissipels se voete te was, behoort ons ook sy voorbeeld na te volg (Joh 13:14-16). $\mathrm{Hy}$ is ons voorbeeld, ons model.

\subsection{Die gawes van die Gees tot diens}

Die diens wat Christus op sy kerk en op sy dissipels lê, stel hoë eise. Ons 
kan dit nie uit onsself doen nie. Daarom gee Hy aan ons sy Heilige Gees. Hierdie Gees wat in die kerk en in die harte van die gelowiges woon, gee aan elkeen soos $\mathrm{Hy}$ wil sy gawes om inderdaad in die kerk en in die wêreld te kan dien. Daar is 'n ryke verskeidenheid van gawes en dit sluit baie nou aan by ons natuurlike gawes. Elkeen het ten minste een gawe ontvang. Niemand het alles ontvang nie. Die gawes verskil van mekaar, maar nie een kan ontbreek nie. Hierdie gawes is nie gegee vir eie vertoon en selfverheffing nie, maar juis om daarmee te dien. Hierdie diens geskied in die kerk, aan die versamelde dissipelgroep, aan mekaar. Dit is altyd diensgawes - daarmee moet ons inderdaad dien.

\subsection{Die motief van dankbaarheid}

Ons kom tot diens omdat ons deel gekry het aan die verlossing deur Jesus Christus. Omdat Hy ons bevry het van die straf en oordeel van God, ons bevry het van die verslawende mag van die sonde en die bose, omdat ons deel gekry het aan die wonderlike verlossing, ingeplant is in sy kerk as sy liggaam, omdat ons lewens weer sin en betekenis gekry het daarom is ons dankbaar, daarom staan ons tot sy beskikking, daarom kan Hy ons in sy diens stel.

Genade bring ons altyd tot die navolging van Jesus en bring ons direk tot medewerking in sy kerk. Genade wat ons nie bring tot navolging en medewerking en diens nie, is goedkoop genade, en genade wat ons tevergeefs ontvang (2 Kor 6:1).

\subsection{Die nood en verlorenheid van die mense}

Uit ' $n$ ander gesigspunt is diens noodsaaklik en kan ons dit nie ontwyk nie. Ons leef in ' $n$ wêreld waar daar uit alle oorde ' $n$ geroep van mense in hulle nood opgaan. Die nood is oral in die wêreld, maar net so ook in die kerk. Die nood het baie vorms: dit is materieel, sosiaal, sielkundig en geestelik. Ten diepste is die nood die verlorenheid van die mens voor God, die gebroke verhouding tot Hom. Uit hierdie een nood vloei vele ander. God wat barmhartig is oor alle mense, veral oor die geringe, verdrukte en verontregte; Christus wat vir die verlorene gesterf het en wat ons roep om sy hulp en bystand teenoor ander uit te dra, skakel sy kerk en elke gelowige in by hierdie diens aan die naaste en aan die medegelowiges. Ons word mede-verantwoordelik gestel vir die broeder en suster en die naaste.

\subsection{Die groot dryfveer van die liefde}

By die diens wat wel moeilik is en offers vra, gaan dit egter nie om 'n 
swaar las wat ons uit dwang en vreugdeloos doen nie. Nee, die dryfveer tot die egte diens is en moet altyd wees: egte liefde. Hierdie liefde kom van God en het veral in Jesus Christus 'n konkrete gestalte gekry. Hierdie liefde vind in ons harte en lewens 'n weerklank. Dit gee aan ons ander oë waarmee ons na mense kyk. Ons kry daardeur ander ore om werklik te luister na ander. Dit gee aan ons die hart wat gevoelig is vir die mens in sy nood. Dit laat ons hande aan die werk gaan en dit bring ons voete in beweging. Die liefde van God in Christus word die groot krag en dryfveer tot diens. Ons kan en wil dien al lyk dit so moeilik, al is daar nie eer en beloning en erkenning aan verbonde nie. Die liefde laat ons besware oorwin, teleurstellings verwerk, laat ons steeds aanhou sonder om moeg te word.

\subsection{Die werk van God en die werk van die mens}

Ons moet steeds daarvan deurdronge wees dat alle diens aan en in die gemeente en van die gemeente in die wêreld, van begin tot einde Gód se werk is. Dit gaan om sý saak, sý koninkryk, sý eer, sý diens. Hierdie waarheid bevry ons van alle selfverheffing, van alle pogings om iets daardeur te wil verdien, van alle teleurstelling waar die gewenste resultate uitbly. Gód se werk is steeds die waarborg dat ons diens sin en betekenis het en dat daarvan iets verwag kan word.

Tegelyk moet met alle klem gehandhaaf word dat alle diens in en aan die kerk die werk van mense is. Dit is diens van mense in belang van mense en dit teenoor mense. Dit is óns werk waarvoor ons alle arbeid en inspanning moet aanwend. Ons is vir hierdie diens verantwoordelik. Ons werk is egter afhanklik van God se werk, en ons werk laat juis sy werk uitkom. In alles moet ons dus dien en werk asof alles van ons afhang. Tegelyk is dit egter altyd in die wete en geloof dat as iets slaag dit alleen God se werk is en in die vertroue dat Hy sy werk wil doen deur ons.

\section{DIE LEWE VAN DIENS EN DIENSBAARHEID}

Die diens en diensbaarheid mond uit in die daaglikse lewe, waar dit "ö̈", "ore", "hande" en "voete" kry.

\subsection{Elke gelowige in diens gestel}

Ons sê gewoonlik dat die leraar 'n roeping ontvang het. Die kerkraadslede is verkies. Hoe staan dit egter nou met die gelowiges? Hulle het nie 
'n "beroep" ontvang nie en hulle is ook nie "verkies" tot 'n bepaalde amp nie. Dus as hulle iets doen en iewers dien is dit bloot vrywillig. Wie dit nie doen nie, hoef nie sleg te voel nie - so lui die redenasie. So iets is totaal verwyder van die waarheid. Elke gelowige is ' $n$ geroepene, is in diens gestel, hét 'n opdrag ontvang, is ingeskakel by die werk van die Here. Elke gelowige word in diens gestel waar hy lidmaat van die kerk word. By die belydenis van sy geloof in Jesus Christus, erken hy Hom as die Here en Hoof van sy lewe, ontvang hy die opdrag om soos sy Meester in die kerk en in die wêreld te dien, stel hy homself in Christus se diens. Hierdie belydenis moet in die lewe waargemaak word en die beloftes uitgevoer word. Die indiensstelling geskied egter al veel eerder. By die doop, waar ons naam saam met die Naam van die drie-enige God genoem word, het die gesprek van God al met ons begin, is ons in sy diens gestel. Ons kan dit nog veel verder terug neem: tot in die verkiesende genade van God, tot in sy Raad. So dikwels leef die gelowiges asof hulle vrygestel is van diens, of die kerk beskou hulle so. lemand het 'n boek geskryf met die titel: God's frozen people. 'n Ander persoon praat van die gelowiges as die "bevrore krediete" van die kerk.

\subsection{Diens en bekering}

Egte diens in die kerk van Christus en in die wêreld hang ten nouste saam met 'n innige verbondenheid met Christus, met die duidelike keuse vir Hom, met die gehoorsaming van Hom. Dikwels vind ons dat mense wel tot bekering kom, werklik glo in Christus, maar dit lei nie tot diens nie. Immers, tussen bekering en diens, tussen bevryding en gehoorsaamheid, tussen hoor en doen, is daar baie steurings en selfs blokkasies. So kan dit gebeur dat mense wel glo, maar nie tot diens of getuienis of gehoorsaamheid kom nie. Daar kom 'n selfgenoegsame vroomheid: die vromes wil vromer word en die heiliges heiliger - en hier pas diens nie.

Vandag is daar weer ' $n$ ander uiterste: mense gaan uit hulle pad om te dien, maar dit is sonder geloof, sonder ' $n$ binding aan Christus. Hierdie diens mag indrukwekkend wees, maar is nie die diens waartoe ons geroep word in die kerk nie. Diens in die kerk en in die wêreld vereis dat bekering en diens onafskeidbaar moet wees. Die begin en voorwaarde van alle diens is en bly die diens wat Christus wakker roep en waarvan Hy die inhoud is en steeds die voorbeeld bly.

\subsection{Geleefde versoening, geleefde geloof}

Die diens wat verlang word en wat saak maak, is waar dit versoening is wat uitgeleef en voorgeleef word, is waar dit geloof is wat geleef, kon- 
kreet word. So kom die evangelie en die geloof by die harde, konkrete lewe, waar mense worstel en waar hulle sensitief word vir die evangelie wat só tot uitdrukking kom.

Geleefde versoening is waar mense so deur Christus en sy verlossing aangegryp is dat hulle in hierdie nuwe lewe volhard, dat hulle sy wil gehoorsaam, sy gesindheid uitdra, sy beeld vertoon, sy diens aan mense betoon, deursigtig word sodat sy liefde uit hulle lewens uitstraal, 'n aantrekkingskrag in die wêreld word wat mense na Christus aantrek. Hier by die geleefde versoening val die beslissing of die kerk en sy lidmate geloofwaardig is of nie.

\subsection{Diens as enkeling en as gemeente}

Elke gelowige word geroep om te dien in die kerk, aan die kerk en ook in die wêreld. Dit geskied op elke vlak van die lewe, waar hy/sy woon en werk, deur die woord en deur die daad, spontaan en miskien ook sistematies. Die gelowige is egter saam met ander gelowiges op pad. God het nie slegs enkelkinders nie. Die gelowiges is op baie maniere verweef met 'n gesin, met 'n gemeenskap, met allerlei groepe.

Die lidmaat is deel veral van die gemeente. Hier leef en werk hy. Hy word gedra en versterk en gevoed deur die gemeente. Op sy beurt help, versorg, versterk en dien hy die gemeente.

\subsection{Solidariteit met die mense}

Wie dien, kan nie op sy troon sit of uit die hoogte raad aan mense gee nie. Hy moet afklim van sy troon en op dieselfde vlak as die mense in leed en nood kom staan. Ons kan ook nie effektief dien as ons letterlik en figuurlik ver van mense af bly staan nie. Wie dien, kom naby die ander, sien hom, luister na hom, voel met hom, raak hom aan, kom in sy skoene staan, kruip in sy vel. Baie goedbedoelde diens word verwerp omdat die mense aanvoel dat ons nie by hulle gekom het nie, nie solidariteit met hulle het nie. Wie dien, deel met andere. ' $n$ Dienende gemeenskap is ' $n$ delende gemeenskap.

\subsection{Diens deur besoekwerk}

Om te kan dien moet ons gaan met liefde en vanuit die regte gesindheid na mense in nood, wat bygestaan, geleer, gelei en opgebeur moet word. Ons moet bý mense kom. Dit alles beteken dat ons nie maar net moet wag dat mense na óns toe moet kom nie. Ons moet juis gaan en mense opsoek waar ons die diens in Christus se Naam moet verrig. Waar 
iemand woon, is sy eie terrein, daar leef en bestaan hy. Dikwels is dit die enigste plek waar ons hom kan bereik. Om iemand te besoek, moet ons weet waar hy woon. Ons moet sy straatadres ken, maar ons moet ook die "adres" ken waar hy met hart en siel tuis is. Veral moet ons sy adres by God ken.

\subsection{Diens en selfverloëning}

Die ware karakter van diens kom daarin uit dat ons te kenne gee ons leef nie meer volgens die ou bedeling, die ou wêreld, die ou "skema", die ou mens nie. Ons toon dat ons hierdie ou mens, hierdie ou self nie ken en gehoorsaam nie. Ons kan onsself verloën, vry kom daarvan om altyd ons eie voordeel te soek en om onsself te draai.

Wie dien, bring offers van tyd, geld, kragte, eie voordele, ja, die eie self. Dien beteken om saam met ander te ly, maar ook om alleen te ly om so groter voordeel vir ander te bring. Nêrens is die dissipels van Jesus groter as wanneer hulle opoffer nie. Wie opoffer en bereid is om te ly om so tot diens te wees van Christus en sy dissipels en die naaste, staan baie naby sy Here en Hoof wat bereid was om te dien tot aan die uiterste van die kruis. So 'n diens het groot krag en rig 'n sterk appèl op mense.

\section{8 'n Duidelike doel met die diens}

Ons omvattende diens geskied nie maar doelloos of sonder plan nie. Daar is ' $n$ duidelike doel waarop ons diens gerig moet wees. Hierdie doel is die bou of die opbou van die kerk sodat dit kan kom tot sy ware betekenis en tot sy volle grootte. Die kerk is egter deel van ' $n$ veel groter geheel wat as doel nagestreef moet word, naamlik die koninkryk van God. Die bou van die koninkryk van God wat gekom het met Christus, wat groei deurdat mense tot geloof kom, maar wat eers voltooi word by die wederkoms van Christus, is die groot doel van al ons diens. Daarvoor kan mens al jou kragte, jou hart en siel, jou hele lewe gee.

Die doel van die. opbou van die kerk en daaragter die bou van die ryk van God, moet altyd reg gesien word. Altyd en eerste is dit Gód wat bou, Hý bou sy koninkryk. Tegelyk gebruik Hy óns as gelowiges om sy koninkryk te help bou. Ons kan sê $\mathrm{Hy}$ bou sy ryk deur die diens van mense.

\subsection{Die opdrag van die evangelie}

Die bou van die kerk en die ryk van God geskied deur die oordrag van die evangelie, die goeie nuus van God se verlossing in Jesus Christus. In ons 
diens, in ons woorde wat van dade vergesel word en daardeur bevestig word, deur ons dade waarop die bevrydende woorde vertel en oorvertel word, gebeur die wonder dat die kerk en die ryk gebou word. Al ons diens staan in die teken van die oordrag van die evangelie.

\subsection{Ruimte vir die gelowiges om te dien}

Om as gelowiges werklik te kan dien en so gebruik te word in die opbou van die kerk en die ryk van God, moet ons diens ook inderdaad nodig geag word. Daar moet vir ons ruimte gemaak word om te dien. Ons moet die geleenthede kry om sinvol te dien. Dikwels in die verlede, byvoorbeeld, is nie die beste gebruik gemaak van die kragte en diens van vroue nie. Hulle moes sulke onbelangrike en selfs sinnelose werk verrig.

Soms kry mens die indruk dat kerkrade en predikante slegs handlangers soek, maar nie medewerkers wat self inisiatief aan die dag lê nie. Gelukkig is die gemeente wat ruimte skep vir die gelowiges om sinvol te werk aan die opbou van die kerk en die ryk van God, wat hulle daartoe toerus, wat hulle daarin vertrou en op daardie weg inspireer.

\subsection{Met alles in sy diens}

God kom na my persoonlik, lê sy hand op my, verander en vernuwe my en eis my op om met alles in sy diens te staan. Die groot vraag is of ek die wonderlike opdrag en tegelyk groot voorreg verstaan. Verstaan ek wat dit beteken dat Hy my roep en gebruik om te dien in sy kerk? Ons kan nou nie meer sê ons het nie verstaan nie.

As ek verstaan het, kom die volgende vraag tot my: kan ook ek in die kerk en in die ryk van God dien? Ek met al my beperkinge en swakhede, kan ek werklik dien? Waar Christus ons ontmoet het, ons verlos het en ons aan Hom gebind het, waar Hy ons toerus met sy Woord en waar Hy ons bekragtig deur sy Gees, kan ons nie meer sê dat ons nie kan nie.

Nou bly daar nog een vraag oor: Wil ek werklik dien in die kerk en koninkryk van God? Hier lê gewoonlik die kern van die probleem: ons wil nie. Maar ons het Hom tog as Here leer ken, ons het ons met alles aan Hom oorgegee, ons het tog sy stem gehoor. Mag ek in ongehoorsaamheid bly sê: ek wil nie? Kar, daar sprake wees van geloof as ons Hom ongehoorsaam bly? Daarom is daar maar een antwoord: Ek het $U$ stem gehoor, o Here! Ek stel myself opreg en sonder reserwe tot $\mathrm{u}$ beskikking en tot u diens. Hier is ek, gebruik my soos $U$ will Dan word die geloof ' $n$ werklikheid en 'n onoorwinlike krag.

En die betaling, die loon vir die diens? In die diens gaan dit eerder 
om te gee as om te ontvang. Tog, die magtige Here wat ons dien is nooit ons skuldenaar nie. Wie Hom dien, sal Hy op sy tyd en op sy wyse beloon. Reeds in hierdie lewe ontvang ons die vreugde om te kan dien. Daar is die vreugde van die seën van die Here. Die eintlike en oorstelpende loon is egter as $\mathrm{Hy}$ aan ons in dié dag sal sê: "Mooi sol Jy is 'n goeie en getroue slaaf. Oor min was jy getrou, oor baie sal ek jou aanstel. Kom in en deel in my vreugde!" (Matt 25:21,23).

\section{LITERATUURLYS}

$\mathrm{H}$ Aichelin, Der religiöse und weltanschauliche Pluralismus der Gegenwart und das Zeugnis der Kirche, in: Gemeinde in diakonischer und missionarischer Verantwortung, (Hrsg T Schober/H Thimmel, Stuttgart s.j.

T Auchter, "Struktuur und Liebe", Wege zum Menschen Jrg 35, 11/12 (1983).

A C Barnard (Red), Die diens van barmhartigheid in Skrif en praktyk, Pretoria 1982.

H M Barth, "Angesichts des Leiden von Gott reden", Pastoraltheologie, 75/3.

I Becker, K H Bieritz, e.a, Handbuch der See/sorge, Berlin 1983.

E Beyruther, Modelle gelebter Frömmigkiet .... Stuttgart s.j.

E Beyruther, "Martyrium und Mission in der alten Kirche", Das Missionarische Wort 1 (1965).

R Boecker, "Selbsthilfegruppen in der Kirchengemeinde", Diakonie 11/4 (1985).

G Boer, "Vancouver over diakonia: delen en helen in gemeenschap", Kerk en Theologie $3 / 1,(1984)$.

$\mathrm{R}$ Bons-Storm, Geloof waardig, stappen op de weg van gemeenteopbouw, Den Haag 1987.

L M Brammer, Het helpende contact, vormen en functie, Haarlem $1978^{5}$.

W Brandt, Der Dienst Jesu, in: Das diakonische Amt der Kirche, (Hrsg H Krimm), Stuttgart $1965^{2}$.

B Cooke, Ministry to word and sacraments, Philadelphia 1976.

K T De Jonge, "Diakonaat en gemeente", Theologia Reformata 29/3 (1986).

J Da Santa Ana, Goed nieuws voor de armen, Kampen 1981.

Diakonia en Koinonia, Algemene Kommissie vir die diens van barmhartigheid, Pretoria 1986.

O Diehm, "Was bedeutet, Christ zu sein?", Das miss. Wort 1 (1987).

G Egan, The skilled helper, Belmont, California $1985^{3}$.

E Fisher, "Verlegenheiten sind Gelegenheiten, zur Führungsproblematik in Diakonie und Gemeinde", Diakonie 12/6 (1986).

O Fuchs, "Ernstfall Diakonie, Christliches Handeln als Verkündigung", TheologischPraktische Quartalschrift 133/3 (1985).

E Gibbs, / believe in church growth, London 1981.

F Gocht, "Die Gemeinde - ein Gesundheitszentrum?" Diakonie 10/5 (1984).

G L Goedhart, Gemeenteopbouw, Kampen 1984.

H Halberstadt, "Leiden und Sirnfrage", Diakonie 1(1984).

J Hendricks, Overal waar mense zijn. De diakonale gemeente, Kampen 19742.

W J Hollenweger, "Heilet die Kranken!", Theologia Practica 22/1 (1987).

J Hansen, "Priestertum aller Gläubigen heute", Das miss Wort 1 (1987).

W Jentsch, Der See/sorger, Moers 1982.

W Jentsch, "Cura animarum", Pastoraltheologie 75/9 (1986).

D J Karres, De gemeente en haar diakonaat, Den Haag 1969. 
G Kiefel, "Existenz und Aktion", Das miss Wort 2 (1969).

F R J Knetsch, "Diakonaat als ambtelijke armenzorg", Nederlands Archief voor Kerkgeschiedenis Deel 64/2 (1984).

H Kunst, "Die Herausforderungen der Weltsituation", in: Diakonie en den Spannungsfeldern der Gegenwart (Hrsg H H Ulrich), Stuttgart 19792.

W Kurz, "Seelsorge als Sinn-Sorge: Zur Analogie von Kirchlicher Seelsorge und Logotherapie". Wege zum Menschen Jrg $37 / 4$ (1985).

H Lilje, "Wenn der Mensch unter Gottes Barmherzigkeit gerăt", Diakonie, $12 / 3$ (1986).

L K Louw, Dienswerk, Proefskrit, Unisa Pretoria 1984.

K Lubkoll, "Auf der Suche nach Mitarbeitern", Das miss Wort 1, (1987).

I Lukatis, U Wesenick (Hrsg), Diakonie - Assenseite der Kirche, Gelnhausen 1980.

H Luther, "Schmerz und Sehnsucht" Theologia Practica 22/4 (1987).

H Luther, "Alltagssorge und Seelsorge: Zur Kritik am Defizitmodell des Helfens", Wege zum Menschen 38/1 (1986).

E Müller, O Basse, e.a., See/sorge in der moderne Gesellschaft, Hamburg 19642.

A Müller-Schöll, "Selbsthilfegruppen - eine Herausforderung an die Diakonie", Diakonie (Jrg) $11 / 4$ (1985).

$\mathrm{K} \mathrm{H}$ Neukamm, "Was wird aus der Diakonie?", Diakonie 10/6 (1984).

K H Neukamm, "Diakonisch leben in einer kranken Welt", Diakonie 13/4 (1987).

A Noordegraff, Gods Boumwerk, Den Haag 1980.

P Ohnesorg, "Gemeindekonzeption und Gemeindeaufbau", Werkstatt Gemeinde 2/6 (1984).

I M Peris, "Krankheit - Gesellschaft - heilende Gott ... ein weites Thema", Diakonie 13/4 (1987).

G W Peters, A theology of church growth, Grand Rapids, Michigan 1981.

P Petersen, "Gefährte meines Leidens", Wege zum Menschen, 35 11/12 (1983).

P Philippi, Christozentrische Diakonie, Stuttgart $1975^{2}$.

P Philippi, Diaconica, Neukirchen-Vluyn 1984.

H C Piper, "Wenn leiden mich trifft", Diakonie 1 (1984).

R Pointer, How do churches grow? Basingstoke 1984.

H Ringeling, "Der diakonische Auftrag der Kirche", Wege zum Menschen, 38/4 (1985).

G Röckle, "Diakonie - gelebte Verkündigung", Diakonie, 11/5 (1985).

P J Roscam-Abbing, Gemeentediakonaat, Den Haag 1979.

H C Schmidt-Lauber, "Diakonie und Seelsorge - Gemeinsames, Proprium und Grenzen". Kervgma und Dogma, 30/3 (1984).

Th Schober, Gedanken zur diakonischen Wortverkündigung (Hrsg F Mykes), Klotz Verlag 1968.

F Schwarz, C A Schwarz, Theologie des Gemeindeaufbaus, Neukirchen-Vluyn $1985^{2}$.

U Spath, "Leiden gemeinsam tragen", Diakonie 12/3 (1986).

D Stollberg, Wenn Gott menschlich wäre, Stuttgart 1978.

Th Strohm, "Theologie der Diakonie - Diakonie an der Theologie", Theologia Practica 3 (1985).

H Tacke, Glaubenshilfe als Lebenschilfe, Neukirchen-Vluyn $1979^{2}$.

D Tidball, Skillful shepherds. Leicester 1986.

C Trimp, Media Vita, Groningen 1981.

C Trimp, De dienst van de mondige kerk, Goes 1971.

H H Ulrich, "Wie evangelisch ist die Diakonie?" Das miss Wort 4 (1978).

J C van Dongen, Diakonia/Charitas, Kampen 1978.

H H von Goesel, "Bekehrung ohne Dienst - Dienst ohne Bekehrung", Dass miss Wort 6 (1966).

H C von Hase, "Diakonie als Zeugnis", Das miss Wort 4 (1979). 
A Walter, "Diakonie als Selbsthilfe christlicher Gemeinde". Theologia Practica 3 (1985). W Wanner, Signale aus der Tiefe, Giessen $1984{ }^{3}$.

H D Wendland, "Diakonie zwischen Kirche und Welt", in: Diakonie swischen Kirche und Welt, (Hrsg C Bourbeck/H D Wendland). Furche Verlag 1958.

J Wiener, H Erharter, Diakonie der Gemeinde, Wien 1978.

W Zauner, "Sorge um die Seele", Theologisch-Praktische Quarta/schrift, 135/(2 (1987).

K Zillesen, "Therapeutische Gemeinde", Diakonie 10/5 (1984). 